\title{
The Epidemic that Shook the World-The Zika Virus Rampage
}

\author{
Ashesh Nandy ${ }^{1 *}$ and Subhash C. Basak ${ }^{2}$ \\ ${ }^{1}$ Centre for Interdisciplinary Research and Education, 404B Jodhpur Park, Kolkata 700068, India; ${ }^{2}$ Natural Resources Research Institute \\ and Department of Chemistry \& Biochemistry, University of Minnesota Duluth, Duluth, MN 55811, USA
}

\begin{abstract}
The sudden emergence in 2015 of neurologically complex infections attributed to the Zika virus (ZIKV) epidemic in Oceania and South America caught the medical and scientific world by surprise. The virus, which was detected often by serological tests, was known to circulate in Africa and in South/South-East Asian countries, causing mild febrile illness accompanied by nausea and aches, and often confused with dengue and chikungunya. How such an apparently benign virus could suddenly become so highly pathogenic-causing unprecedented levels of infections and an epidemic that affected fetuses in pregnant women to manifest microcephaly and other neurological disorders in newborns - is not yet understood, nor are there any drugs or vaccines to inhibit its progress. In this review, we recount the epidemiological aspects of the ZIKV spread, its clinical manifestations and diagnosis, and the genetics of the virus; we also narrate the efforts to understand the causes of the epidemic strains and discuss different designs of preventives and therapeutics.
\end{abstract}

Introduction

A sudden increase in number of neonatal microcephaly cases in north eastern Brazil in early 2015 brought out, in stark contrast, the devastation caused by a till-then little known virus, first isolated in the Zika forest of distant Uganda almost 70 years ago and since known as the Zika virus(ZIKV). ${ }^{1}$ The ZIKV zoonotic cycle, transmitted primarily by the Aedes aegypti mosquito, transformed into a human-mosquito cycle and gradually spread across tropical Africa and later in Asia, until it leapt through Oceania to cause an epidemic in Yap Island in Micronesia in 2007 and in French Polynesia in 2013. Higher frequency of international travel, increase in the active range of the vectors due to global warming as well as vulnerability of isolated populations played a part in this expansion, perhaps to various degrees. ${ }^{2,3}$ However, it was the epidemic of microcephaly discovered in Brazil in 2015 that focused attention on the Zika virus. ${ }^{4}$

While some symptoms are similar to dengue (DENV) and chi-

Keywords: Zika virus; Epidemiology; Geographical distribution; Transmission; Clinical manifestations; Diagnosis; Treatment; Prevention; Genome; Proteins; Drugs; Vaccines.

Abbreviations: 2D, two-dimensional; C, capsid; CDC, Centre for Disease Control and Prevention; DENV, dengue; E, envelope; GBS, Guillain-Barre syndrome; JEV, Japanese encephalitis virus; MT, methyltransferase; NIAID, National Institute of A1lergic and Infectious Diseases; NS, non-structural; PHEIC, Public Health Emergency of International Concern; prM/M, pre-membrane/membrane; SPONV, Spondweni virus; UTRs, untranslated regions; WHO, World Health Organization; WNV, West Nile virus; ZIKV, Zika virus.

Received: June 21, 2017; Revised: July 29, 2017; Accepted: August 11, 2017

*Correspondence to: Ashesh Nandy, Centre for Interdisciplinary Research and Education, 404B Jodhpur Park, Kolkata 700068, India. E-mail: anandy43@yahoo.com

How to cite this article: Nandy A, Basak SC. The Epidemic that Shook the World-The Zika Virus Rampage. Exploratory Research and Hypothesis in Medicine 2017;2(3): 43-56. doi: 10.14218/ERHM.2017.00018. kungunya, neurological complications arising out of ZIKV infections were a new phenomenon to contend with, and like in case of other viral epidemics, drugs and vaccines for therapeutics or preventives for the ZIKV are yet to be developed. In this review, we outline the current status of the geographical extent of this virus, its epidemiology, transmission and clinical symptoms, and proceed to discuss in some detail the genetics of the ZIKV, the probable causes of the Zika epidemic and current status of the development of drugs and vaccines against the virus.

\section{ZIKV Epidemiology}

\section{Geographical distribution of the ZIKV}

The virus was first isolated in April 1947 in a sentinel rhesus monkey (Rhesus 766) caged in the canopy of the lush Zika (meaning "overgrown" in the local Luganda language) forest of Uganda, by the side of Lake Victoria, during a study of yellow fever immunity of monkeys in the Entebbe peninsula; the virus was subsequently identified and named as the ZIKV. ${ }^{1}$ The virus was also found in the A. africanus mosquitoes in the following year, indicating a sylvatic cycle of infection and transmission through the arthropods.

Human infection was suspected from a serosurvey of residents of areas nearby the Zika region in 1951, which revealed presence of ZIKV antibodies. ${ }^{5}$ While the first identified Zika infection was commonly believed to be in Nigeria in 1954, recent reports indicate that the first laboratory confirmed cases of Zika infection in humans were in Uganda, Tanzania and India in 1952, then in 1953 in Nigeria, Malaya, Borneo and the Philippines, and in more countries in Equatorial Africa and Asia in subsequent years. ${ }^{3}$

A concise summary of all Zika viral infections and detections in 
Table 1. Zika virus detected from 1947, the pre-epidemic period

\begin{tabular}{|c|c|c|}
\hline Year & Country & Remarks \\
\hline 1947 & Uganda & $\begin{array}{l}\text { First isolation and identification of ZIKV. Found in } \\
\text { rhesus monkey, R766, caged in Zika forest. }\end{array}$ \\
\hline 1948 & Uganda & Detected in A. africanus mosquitoes. Found in Zika forest. \\
\hline 1951 & Nigeria & First instance of ZIKV antibodies in human blood, found in children. \\
\hline \multirow[t]{2}{*}{1952} & Uganda, Tanganyika & First human cases of ZIKV infection detected. \\
\hline & India & ZIKV antibodies found in human blood. \\
\hline \multirow[t]{2}{*}{1953} & Malaya, North Borneo, Philippines & ZIKV antibodies found in residents. \\
\hline & Nigeria & ZIKV infection detected in three persons. \\
\hline 1954 & Egypt, Vietnam & ZIKV antibodies found in few residents. \\
\hline 1955 & Nigeria & ZIKV antibodies found in human blood. \\
\hline 1957 & Mozambique & ZIKV antibodies found in human blood. \\
\hline 1958 & Uganda & Two strains of ZIKV found in A. aegypti mosquitoes in Zika forest. \\
\hline 1960 & Angola & ZIKV antibodies found in indigenous residents. \\
\hline $1961-62$ & Central African Republic & ZIKV antibodies found in human blood. \\
\hline $1961-64$ & Ethiopia & ZIKV antibodies found in human blood. \\
\hline 1962 & Senegal & ZIKV antibodies found in human blood. \\
\hline $1963-64$ & $\begin{array}{l}\text { Central African Republic, } \\
\text { Burkina-Faso }\end{array}$ & ZIKV antibodies found in human blood. \\
\hline $1963-65$ & Ivory Coast & ZIKV antibodies found in human blood. \\
\hline 1964 & Uganda & $\begin{array}{l}\text { First confirmation that ZIKV causes human disease. } \\
\text { Clinical features reported. }\end{array}$ \\
\hline $1964-65$ & Guinea-Bissau & ZIKV antibodies found in human blood. \\
\hline 1964-66 & Togo, Cameroon & ZIKV antibodies found in human blood. \\
\hline 1965 & Niger & ZIKV antibodies found in human blood. \\
\hline $1965-67$ & Nigeria & ZIKV antibodies found in human blood. \\
\hline 1967 & Benin, Gabon, Liberia & ZIKV antibodies found in human blood. \\
\hline $1966-67$ & Uganda, Kenya, Somalia, Morocco & ZIKV antibodies found in human blood. \\
\hline 1967-69 & Uganda & ZIKV antibodies found in human blood. \\
\hline 1968 & Kenya & ZIKV antibodies found in human blood. \\
\hline 1969-72 & Nigeria & ZIKV antibodies found in human blood. \\
\hline 1969 & Malaysia & ZIKV found in A. aegypti mosquitoes. \\
\hline 1969-83 & Indonesia, Malaysia, Pakistan & $\begin{array}{l}\text { ZIKV found in mosquitoes. } \\
\text { Sporadic human infections. }\end{array}$ \\
\hline 1970 & Nigeria & ZIKV antibodies found in human blood. \\
\hline 1971-72 & Angola & ZIKV antibodies found in human blood. \\
\hline $1972,1975,1988,1990$ & Senegal & ZIKV antibodies found in human blood. \\
\hline 1979 & Central African Republic & ZIKV antibodies found in human blood. \\
\hline 1980 & Nigeria & ZIKV antibodies found in human blood. \\
\hline 1984 & Uganda & ZIKV antibodies found in human blood. \\
\hline 1996-97 & Malaysia & ZIKV antibodies found in human blood. \\
\hline 1999 & Ivory Coast & ZIKV antibodies found in human blood. \\
\hline
\end{tabular}

Abbreviations: A. africanus, Aedes africanus; ZIKV, Zika virus. 


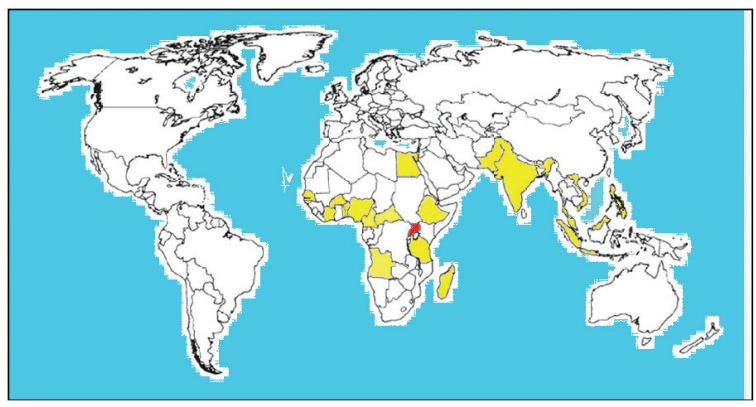

Fig. 1. World map of areas where ZIKV infections were detected in the pre-epidemic period. Uganda, where the virus was first detected, is shaded red. The remaining infected areas are shaded yellow. Abbreviation: ZIKV, Zika virus.

the years prior to the first epidemic is given in Table 1 and a world map of these areas is presented in Figure 1. In all these cases, the infected persons reported mild fevers, headaches and body pains, symptoms often confused with DENV and chikungunya, two other viral diseases that are often endemic in the same areas and are transmitted by the same vectors. Indeed, this may have caused many Zika infections to be mistaken as DENV or chikungunya. Moreover, such symptoms led Zika viral disease to be considered as benign all through the $20^{\text {th }}$ century.

The first reported outbreak of the ZIKV was from Yap Island in the Federated States of Micronesia in 2007, where about 5,000 of the 6,700 residents were infected. The next outbreak was reported from French Polynesia, affecting around 32,000 people, where instances of Guillain-Barre syndrome (GBS), a disease that causes muscle weakness from damage to the peripheral nervous system, were also indicated. Further outbreaks occurred in the Pacific at Easter Islands, New Caledonia and Cook Islands in 2014 and in Samoa in 2015, whereas only sporadic instances of Zika infections were reported from countries in Asia. ${ }^{5}$

The most massive outbreak occurred in early 2015 in Brazil, South America, where the ZIKV spread rapidly from the initial location around Bahia to the contiguous states, ${ }^{4}$ leading the local government to report about 1.3 million infections by December 2015 (see Ref. [3] for detailed descriptions) Neighboring Colombia reported Zika infections by early 2016, and by April 2017, 48 countries in the Americas had reported autochthonous vector-borne transmission of the ZIKV leading to tens of thousands of cases of Zika infections. ${ }^{6}$ Table 2 provides a brief timeline of these outbreaks.

What was a shocking surprise was the several thousand neonatal microcephaly cases observed in the regions with ZIKV epidemic; subsequent analysis of the earlier French Polynesian outbreak showed a high level of neonatal microcephaly there also. This and other neurological disorders, such as GBS, were totally unexpected in scope and effect. Some Latin American countries advised their citizens to avoid pregnancies until the new virus was well understood $^{7}$; the WHO responded by declaring a Public Health Emergency of International Concern (PHEIC) in February 2016, and relaxed it only in November of that same year. ${ }^{8}$

Cumulative data of cases of Zika viral infections and neurological disorders in the Americas following the epidemic are summarized region wise in Table 3 . The scale of the incidence of microcephaly associated with ZIKV infections can be judged from the following data: the Centre for Disease Control and Prevention (CDC) of the U.S. Department of Health \& Human Services (USA) estimated that microcephaly can occur at between 2 and 12 per 10,000 live births in the USA under normal circumstances9; and a study in India of neonatal microcephaly determined a rate of 2.3 per 10,000 births, similar to European estimates. ${ }^{10}$ The number of actual live births in the Americas between 2015 and May 2017 is not known, but the CDC estimated that among the 1,297 pregnancies reported in 2016 in the USA with suspected cases of ZIKV infection, laboratory confirmed cases of such infection showed a result that 1 in every 10 fetuses or infants with Zika-related development or birth defects, a considerably large number compared to normal circumstances. ${ }^{1}$

\section{Transmission}

From shortly after the discovery and identification of ZIKV, it was clear that transmission of the virus from animal to animal occurred through arthropods, of which $A$. africanus was the first to be identified (Table 1). ${ }^{1}$ The sylvatic cycle of transmission between nonhuman primates and mosquitoes prevalent in Africa was not observed in Asia, but subsequently a human-mosquito-human cycle of ZIKV infection came into being as the virus adapted to human hosts5. The primary arthropods identified in this cycle represented several subgroups of the Aedes mosquitoes. Two subspecies, $A$. aegypti and $A$. albopictus, have been found to be the main vectors of the disease of which the A. aegypti is the prime vector. It is relevant to note that the $A$, aegypti and other Aedes mosquitoes are also vectors for DENV and chikungunya viruses.

It is variously believed that the spread of ZIKV in recent years may have been caused by an infected traveler arriving at a new place, or perhaps an infected mosquito being inadvertently carried to the new place through various transports, ${ }^{12,13}$ possibilities that cannot be discounted in today's world, where frequent travel and communications are commonplace. This may have happened before too, but the effect in Africa and Asia is believed to have been muted, due perhaps to immunities developed over many closely related viral and other diseases such as malaria, DENV and chikungunya. Such immunity may not have been indigent in Oceanian and American populations and, therefore, could have been the cause behind the large outbreaks there. ${ }^{3}$

Transmission of ZIKV can also be carried out by several other routes, including vertical transmission between mother and fetus through the placental barrier, sexual acts like vaginal, oral and anal sex, blood transfusions and organ transplants as well as laboratory exposure to the virus. Such exposures have led ZIKV RNA to be detected in urine, semen, female genital tract secretions, blood, saliva, breast milk, cerebrospinal fluid and amniotic fluid. These have been detected from between 1 week after onset of illness to about 6 months after, and human-to-human transmission is also suspected through body fluids, such as tears or sweat. ${ }^{14}$

\section{Clinical manifestations}

Onset of ZIKV illness takes place generally from 2 days to 2 weeks after being bitten by an infected mosquito in about $20-25 \%$ cases; the rest of the cases being asymptotic. ${ }^{14,15}$ The illness is usually mild, resolves in within a week, and provides immunity to further attacks. ${ }^{14}$ Symptoms typically include, inter alia, acute but low fever, body rash (especially in the face and trunk), headache, arthralgia and conjunctivitis, and less commonly including diarrhea, abdominal pain, etc. In children, intrauterine and intrapartum infections through vertical transmissions have been observed, but there have been no developmental problems reported in children who were infected after delivery.

As mentioned earlier, several of these symptoms are similar to 
Table 2. ZIKV epidemics, 2007 to present

\begin{tabular}{|c|c|c|}
\hline Year & Country & Remarks \\
\hline 2007 & Yap Island, Micronesia & First outbreak reported in humans. \\
\hline 2008 & Senegal & $\begin{array}{l}\text { First reported case of traveler infected in Senegal returning to home country and passing } \\
\text { infection through sexual contact. }\end{array}$ \\
\hline 2010 & Cameroon & ZIKV antibodies found in human blood. \\
\hline 2010-2015 & $\begin{array}{l}\text { Cambodia, Indonesia, } \\
\text { Malaysia, Philippines, } \\
\text { Thailand, Maldives }\end{array}$ & $\begin{array}{l}\text { Mosquito transmission of ZIKV in these countries to travelers who then carried the } \\
\text { infection to their home countries. }\end{array}$ \\
\hline 2011-2014 & French Polynesia & $\begin{array}{l}\text { Second reported outbreak of ZIKV infections. Connection with microcephaly and } \\
\text { neurological disorders established later. }\end{array}$ \\
\hline 2013-2014 & $\begin{array}{l}\text { Chile, Cook Islands, } \\
\text { New Caledonia }\end{array}$ & ZIKV outbreak. \\
\hline 2013 & Tahiti & ZIKV isolated from patient's semen showing sexual transmissibility. \\
\hline 2014 & Zambia & ZIKV antibodies found in human blood. \\
\hline 2015 April/May & Brazil, Bahia state & $\begin{array}{l}\text { National Reference Laboratory, Brazil confirmed, by PCR, ZIKV infections, for the first time } \\
\text { in the Americas. }\end{array}$ \\
\hline 2015 July & Brazil & $\begin{array}{l}\text { Zika cases confirmed by laboratory tests in } 12 \text { states. } \\
\text { Neurological disorders associated with prior viral infections detected primarily in the } \\
\text { Bahia region. }\end{array}$ \\
\hline 2015 October & South America & $\begin{array}{l}\text { Colombia, Republic of Cabo Verde report confirmed cases of ZIKV infections. } \\
\text { Brazil reported unusual increase in the number of cases of neonatal microcephaly. }\end{array}$ \\
\hline 2015 November & $\begin{array}{l}\text { Central and } \\
\text { South America }\end{array}$ & $\begin{array}{l}\text { Brazil reported } 141 \text { suspected cases of microcephaly and declared a national public health } \\
\text { emergency. } \\
\text { Brazil reported detection of ZIKV in amniotic fluid of fetuses with confirmed microcephaly. } \\
\text { Suriname, Panama, El Salvador, Guatemala and Paraguay confirmed cases of ZIKV } \\
\text { infection. } \\
\text { The Pan American Health Organization and WHO issued an epidemiological alert. }\end{array}$ \\
\hline 2015 November & Mexico & Three cases of ZIKV infection confirmed by PCR. \\
\hline 2015 November & French Polynesia & $\begin{array}{l}\text { Retrospective analysis reveals unusually large number of central nervous system } \\
\text { malformations in fetuses and infants in 2014-2015. }\end{array}$ \\
\hline 2015 December & $\begin{array}{l}\text { Central and } \\
\text { South America }\end{array}$ & Honduras, French Guiana and Martinique reported confirmed cases of ZIKV infections. \\
\hline 2015 December & Puerto Rico & First confirmed case of Zika infection reported. \\
\hline 2016 & Maldives & Finnish national working in Maldivestested positive for Zika after return to Finland. \\
\hline 2016 January & Americas & $\begin{array}{l}\text { Guyana reported the first PCR-confirmed case of locally acquired Zika infection. } \\
\text { Ecuador, Bolivia, Barbados, Haiti, Dominican Republic, Nicaragua, Curacao and Jamaica } \\
\text { reported the first confirmed cases of Zika infections. } \\
\text { First case of Zika in St. Martin reported. }\end{array}$ \\
\hline 2016 January & US Virgin Islands & First confirmed case of Zika in St. Croix reported. \\
\hline 2016 February & Americas & $\begin{array}{l}\text { First confirmed case of ZIKV infection in Chile reported. } \\
\text { First case of sexually transmitted Zika infection in Texas, USA reported. }\end{array}$ \\
\hline 2016 & Various countries & $\begin{array}{l}\text { Angola, Antigua, British Virgin Islands, Trinidad and Tobago, Guadulope, Fiji, Marshall } \\
\text { Islands, Papua New Guinea, and other countries report first cases of ZIKV infections. }\end{array}$ \\
\hline 2016 & Singapore & ZIKVinfection reported. \\
\hline $2016 / 2017$ & India & Three cases of ZIKV infection reported in Ahmedabad. \\
\hline 2017 & Singapore & Several cases of locally transmitted ZIKVconfirmed. \\
\hline
\end{tabular}

Data summarized from source: (1) Kindhauser et al. ${ }^{3}$; (2) WHO Situation Report on Zika Virus, $9^{\text {th }}$ March 2017. http://apps.who.int/iris/bitstream/10665/254714/1/zikasitrep10Mar17-eng.pdf?ua=1

Abbreviations: ZIKV, Zika virus. 
Table 3. Cumulative cases of ZIKV infection in the Americas 2015-2017 as of 11 May 2017

\begin{tabular}{lllll}
\hline Region* & Confirmed autochthonus cases & Imported cases & $\begin{array}{l}\text { Deaths from } \\
\text { ZlKVinfection }\end{array}$ & $\begin{array}{l}\text { Confirmed congenital syndrome } \\
\text { associated with ZIKV infection }\end{array}$ \\
\hline North America & 225 & 5,478 & 0 & 67 \\
Latin America (Mexico) & 8,731 & 15 & 0 & 5 \\
Central American Isthmus & 6,309 & 77 & 0 & 81 \\
Latin Caribbean & 41,823 & 205 & 5 & 143 \\
Andean area & 15,136 & 41 & 0 & 167 \\
Brazil & 133,527 & 0 & 11 & 2,653 \\
Southern cone & 100 & 75 & 0 & 4 \\
Non-Latin Caribbean & 5,649 & 29 & 4 & 10 \\
TOTAL & 211,500 & 5,920 & 20 & 3,130 \\
\hline
\end{tabular}

*Regions defined as follows: North America: Bermuda, Canada, United States of America; Central American Isthmus: Belize, Costa Rica, El Salvador, Guatemala, Honduras, Nicaragua, Panama;Latin Caribbean: Cuba, Dominican Republic, French Guiana, Guadeloupe, Haiti, Martinique, Puerto Rico, St Barthelemy, St Martin; Andean Region: Bolivia, Colombia, Ecuador, Peru; Southern cone: Argentina, Chile, Paraguay, Uruguay; Non-Latin Caribbean: Anguilla, Antigua and Barbuda, Aruba, Bahamas, Barbados, Bonaire, St Eustatius and Saba, Cayman Islands, Curacao, Dominica, Grenada, Guyana, Jamaica, Montserrat, St Kitts and Nevis, St Lucia, St Vincent and the Grenadines, St Maarten, Suriname, Trinidad and Tobago, Turks and Caicos Islands, Virgin Islands (UK), Virgin Islands (USA).

Data summarized from source: Pan American Health Organization/World Health Organization. Zika suspected and confirmed cases reported by countries and territories in the Americas Cumulative cases, 2015-2017. Updated as of 11 May 2017. Washington, D.C.: PAHO/WHO; 2017; Pan American Health Organization • www.paho.org • (c) PAHO/WHO, 2017

Abbreviation: ZIKV, Zika virus.

those for DENV, chikungunya and many other diseases, leading to misinterpretation of many ZIKV cases as DENV or chikungunya, especially considering the years of experience of treating these diseases. The Pan American Health Organization, based on the experience gained from the French Polynesian outbreak, issued a provisional case definition (that ZIKV infection is to be suspected when a patient shows a low grade body temperature $(>37.2$ ${ }^{\circ} \mathrm{C}$ ) and one or more of the following symptoms (not explained by other medical conditions): arthralgia or myalgia; non-purulent conjunctivitis or conjunctival hyperemia; headache or malaise. ${ }^{16}$ A confirmed case is a suspected case with a positive laboratory result, specifically for detection of ZIKV. Musso and Gubler further specified temperature range as $37.8-38.5^{\circ} \mathrm{C}$ for Zika infection accompanied by pruritic rash (on face, trunk, extremities, soles), ${ }^{17}$ arthralgia and conjunctivitis (nonpurulent); indeed, conjunctivitis seems contra-indicated for DENV, chikungunya and other diseases with similar symptoms. ${ }^{14}$

The damaging effect of ZIKV became apparent only when Zika viral infections in pregnant mothers resulted in unusually high incidence of neonatal microcephaly and other neurological disorders (Table 3). The full range of anomalies in children born from women who had been infected with ZIKV during pregnancy is yet to be understood; a perspective on fetal ZIKV impact can be gleaned from the review by Cayne and Lazear. ${ }^{18}$ Severe cases of microcephaly have been seen to arrest intellectual development, slowdown physical development, affect locomotion, and, in some cases, lead to early death (see Ref. [17] for details of Zika clinical manifestations). The severity of the impact of this disease led several Latin American countries to advise precautionary steps for their citizens and other countries issued advisories against avoidable travel to countries where ZIKV infections have been noted (see e.g., Ref. [19]). ${ }^{20}$

A rare but notable neurological disorder, GBS has been reported from areas in Oceania and the Americas where there had been ZIKV outbreaks, ${ }^{5}$ with a short time lag. ${ }^{17}$ In French Polynesia, a study of patients with GBS and electrophysiological patterns compatible with acute motor axonal neuropathy detected anti-glycolipid antibody activities in the serum, particularly against the GA1 ganglioside. ${ }^{21}$ A study in Colombia evaluated 68 GBS patients in 2015-16 and found $97 \%$ had Zika infections within a month prior to the onset of the symptoms. Among those who could be tested with nerve-conduction studies, $78 \%$ suffered from the acute inflammatory demyelinating polyneuropathy subtype of GBS. ${ }^{22}$

ZIKV outbreaks and incidences of microcephaly in newborns in the Americas led the Pan American Health Organization and the WHO to declare several epidemiological alerts through $2015 .^{16,23,24}$ By early 2016, the burden of circumstantial evidence of a link between ZIKV infection and congenital abnormalities and neurological disorders had become acute enough for the WHO to declare on 1 February 2016 the virus as a PHEIC. Later, on 18 November 2016, the WHO Emergency Committee concluded that the ZIKV and associated consequences constitute a significant and enduring public health challenge requiring intense action but no longer representing a PHEIC. ${ }^{8}$

By the end of 2016, the virus had spread north to 44 states of the USA and to all US Territories (Fig. 2), with reports of microcephaly, neurological disorders, eye abnormalities and other consequences of dysfunction of the central nervous system in newborns. Reportedly, $15 \%$ of fetuses/infants born to women with confirmed ZIKV infection in the first trimester showed birth defects. ${ }^{11}$ The statistics up to 24 May 2017 showed that the US states including District of Columbia had 5,300 cases of ZIKV infections, and that there were 36,582 cases in US Territories, as reported to ArboNet. ${ }^{25}$ However, in South America the number of suspected and confirmed cases of ZIKV infection appear to be decreasing of late. ${ }^{6}$ On the other hand, three cases of ZIKV infection have been confirmed by laboratory tests in Ahmedabad, India in 2016 and recently reported ${ }^{26}$; the Government of India is taking steps to contain the spread of the virus.

\section{Diagnosis}

Diagnosis of ZIKV infection has been a difficult problem. As mentioned earlier, the symptoms bear close resemblance to DENV and 


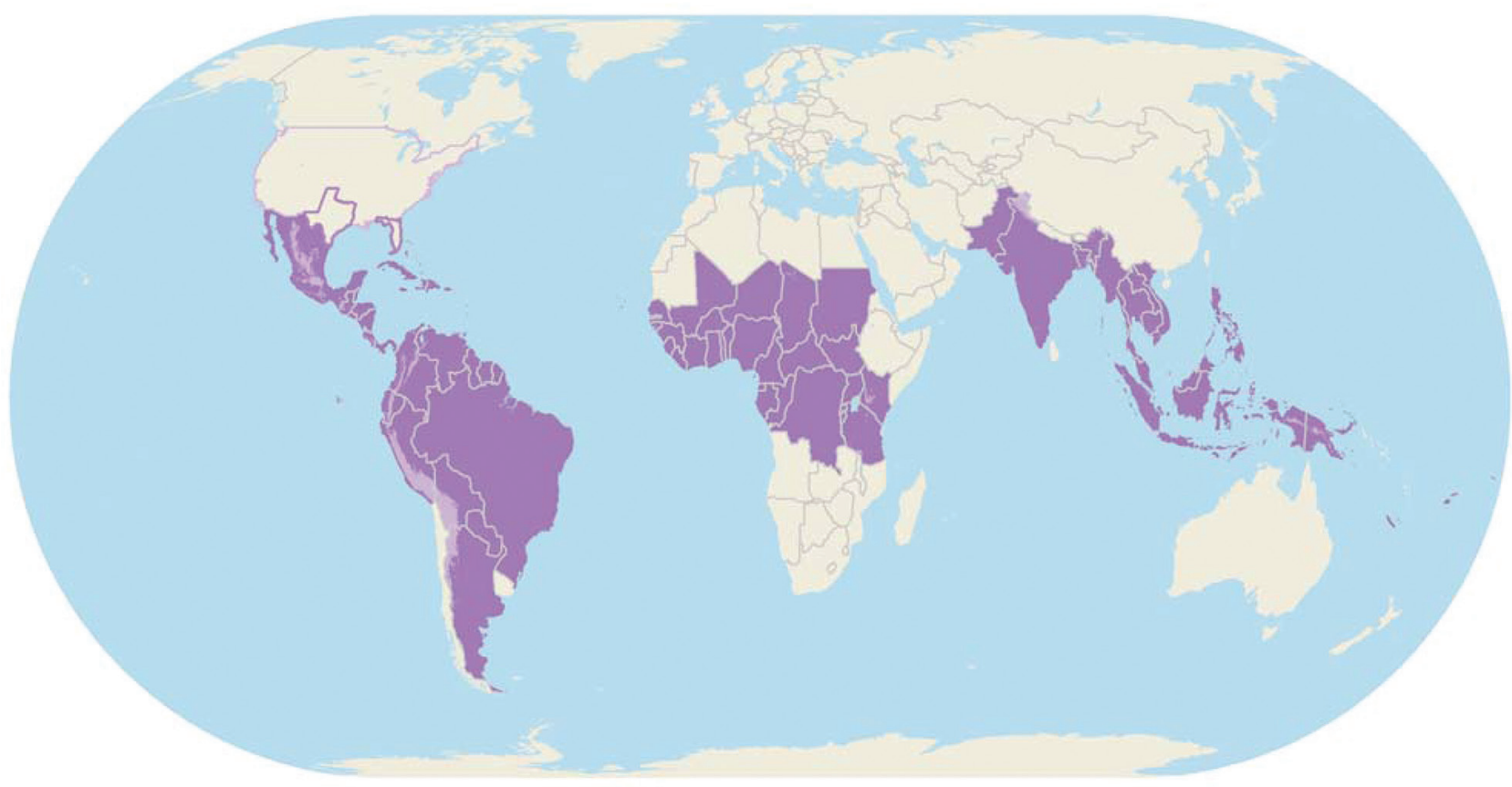

International areas and US territories

Areas with risk of Zika infection (below 6,500 feet)*

Areas with low likelihood of Zika infection (above 6,500 feet)*

Areas with no known risk of Zika infection
United States areas

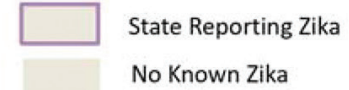

No Known Zika

Fig. 2. World map of areas with risk of ZIKV. Mosquitoes that can spread Zika usually live in places below 6,500 feet. The chances of getting Zika from mosquitoes living above that height are very low. Abbreviation: ZIKV, Zika virus. Map as of August $5^{\text {th }}$, 2017. https://wwwnc.cdc.gov/travel/page/world-mapareas-with-zika Reproduced with permission from CDC (Ref: INQ 11665 GEN).

chikungunya infections which are carried by the same vectors. Both latter infections, however, lead to high fever and body aches but are not associated with conjunctivitis, which is seen in case of Zika infections. There are similarities in symptoms with other viral diseases as well, from enterovirus and adenovirus to alphaviruses which also cause arthritis.

Diagnosis of the actual cause of infection has to be determined in qualified laboratories through serological tests or reverse transcription-polymerase chain reaction, ${ }^{14}$ which is time consuming. Efforts are being undertaken to develop equipment to make accurate diagnosis easier; for example, Sandia has developed a simple kit with smartphone app that the company claims will solve this issue while requiring very little training. ${ }^{27}$

\section{Treating patients with Zika viral infection}

There are no medicines for treating ZIKV patients. The standard procedure is to treat the symptoms. ${ }^{28}$ The patient is to be advised plenty of rest, liberal fluid intake to prevent dehydration, and some medicines, such as acetaminophen, to reduce fever. Aspirin, nimesulide and other anti-inflammatory drugs are to be avoided until DENV is ruled out by tests to avoid hemorrhage. For other medications, patients should consult their physicians.

For further precautionary measures, the patient should be kept in a mosquito-free environment to prevent spread of the disease.
Those caring for the patient need to protect themselves from contamination through body fluids, bites by infected mosquitoes, or from handling infected clothing and other materials.

\section{Prevention of infections from $Z I K V$}

Since there are no prophylactics or therapeutics against the ZIKV, prevention of infection is the best recourse. The primary societal measure has to be control of the vectors that spread the disease, but this has proved to be extremely difficult. Brazil, for instance, had tried to eradicate the $A$. aegypti mosquitoes in their bid to arrest the spread of DENV in the pre-Zika period, but results have not been satisfactory. ${ }^{29}$ At the individual level the following steps are recommended (see also Ref. [30]):

1. Use mosquito nets and repellants to prevent mosquito bites. Wear long-sleeved clothing, as far as practical, for self and children. Use screens on windows and doors.

2. Avoid travel to areas known to have Zika viral infections, unless absolutely necessary. Check CDC and other travel advisories before undertaking a journey to Zika viral risk prone areas.

3. Keep yourself as secluded from contact with people as possible for several weeks if you have travelled to Zika prone areas.

4. Protect yourself and your partner during sexual contacts if either of you have risk of Zika infection.

5. Women need to be even more vigilant against the virus dur- 
Table 4. Structure of a typical flavivirus genome including UTRs

\begin{tabular}{|c|c|c|c|c|c|}
\hline Srl No & Gene & Sequence span,nt & Sequence length* & Protein/function & References \\
\hline 1 & $5^{\prime}$-UTR & $1-107$ & 107 & Encodes regions essential for genome cyclization/replication. & [34] \\
\hline 2 & Capsid & $108-473$ & 366 & Virion structure. & [34] \\
\hline 3 & $\mathrm{prM} / \mathrm{M}$ & 474-977 & 504 & $\begin{array}{l}\text { prM forms heterodimers with } \mathrm{E} \text { to form immature virion. } \\
\text { prM then cleaved and mature virions formed with } \mathrm{M} \text {. }\end{array}$ & [34] \\
\hline 4 & $\mathrm{E}$ & $978-2,489$ & 1,512 & Viral entry into host cell. & [36] \\
\hline 5 & NS1 & $2,490-3,545$ & 1,056 & Viral replication, immune evasion, genome synthesis. & {$[37,38]$} \\
\hline 6 & NS2A & $3,546-4,223$ & 678 & $\begin{array}{l}\text { Transmembrane protein, part of replication } \\
\text { complex; assembly/secretion of virus particles. }\end{array}$ & [35] \\
\hline 7 & NS2B & $4,224-4,613$ & 390 & Cofactor for proteinase domain of NS3; proteolytic processing. & [35] \\
\hline 8 & NS3 & $4,614-6,464$ & 1,851 & Protease/helicase. & {$[39,40]$} \\
\hline 9 & NS4A & $6,465-6,914$ & 381 & Viral RNA replication and amplification. & [35] \\
\hline 10 & $2 \mathrm{~K}$ & $6,846-6,914$ & 69 & $\begin{array}{l}\text { Peptide generated by cleavage at the } \mathrm{N} \\
\text { terminus of the NS4B signal sequence. }\end{array}$ & [35] \\
\hline 11 & NS4B & $6,915-7,667$ & 753 & $\begin{array}{l}\text { Facilitates viral replication complexes; } \\
\text { counteracts innate immune responses. }\end{array}$ & [35] \\
\hline 12 & NS5 & $7,668-10,376$ & 2,709 & Methyltransferase; RNA-dependent RNA polymerase. & [41] \\
\hline 13 & 3'-UTR & $10,380-10,807$ & 427 & Facilitates viral replication and translation. & [34] \\
\hline
\end{tabular}

*Typical length data taken from ZIKV isolate ZIKV/H.sapiens/Brazil/PE243/2015 (GenBank Locus ID KX197192), complete genome.

Abbreviations: E, envelope; NS, non-structural; nt, nucleotide; prM/M,pre-membrane/membrane; UTR, untranslated region.

ing pregnancies. ${ }^{31}$

\section{Genetics of ZIKV}

Although the ZIKV was isolated about 70 years ago and Bayesian evolutionary analysis estimates that the virus actually evolved between 1892 and 1943, it was little studied until very recently. The ZIKV is one species in the genus Flavivirus, family Flaviviridae, comprising a group of about 70 viruses, some of which are human-infecting, such as DENV, yellow fever virus, West Nile virus (WNV) and Japanese encephalitis virus (JEV). The most prominent mode of transmission of these viruses is by arthropod vectors such as ticks and mosquitoes, mainly of the Aedes species.

The ZIKV is also closely related to the Spondweni virus (SPONV), a flavivirus that is also transmitted by the Aedes species, with which the ZIKV has a nucleotide and amino acid identity covering a range of $68.3 \%$ to $69.0 \%$ and $74.6 \%$ to $75 \%$, respectively, when compared with a group of nine ZIKV strains. ${ }^{32}$ The SPONV has been prevalent in Africa among cattle and other animals and only sporadically infecting humans, but its reservoir host is not known. The ZIKV, on the other hand, has adapted to human hosts and spread through Africa and Asia, causing the recent epidemics in Oceania and the New World. These events and other reports suggest that the SPONV and ZIKV are different species in the same Flavivirus family, but the low level of SPONV infection and spread compared to ZIKV with essentially the same vectors suggest they have low potential for SPONV transmissibility vis a vis ZIKV. ${ }^{32,33}$

\section{The ZIKV genome}

The human infecting arboviruses mentioned above are positivesense, single-stranded, RNA viruses between 40 and $65 \mathrm{~nm}$ long, and enveloped with icosahedral-like structures containing linear, non-segmented genomes of around 10 to $11 \mathrm{~kb}$ in length encoding 10 proteins, including three structural proteins of capsid (C), premembrane/membrane (prM/M) and envelope (E) and seven nonstructural (NS) proteins of NS1, NS2A, NS2B, NS3, NS4A, NS4B and NS5 (a " $2 \mathrm{~K}$ " 23 amino acid peptide is generated by cleavage of the N terminus of the NS4B signal sequence) ${ }^{34}$ Like the other flaviviruses, the ZIKV genome has flanking untranslated regions (UTRs) at the 5'- and the 3 '-end with around 107 (5'-end) and 428 ( $3^{\prime}$-end) nucleotides, respectively. The genome structure is summarized in Table $4 .{ }^{34-41}$

Phylogenetic analysis of complete genomes of the ZIKV (Fig. $3)^{42}$ shows two distinct clades: African and non-African or Asian. The African clade is subdivided roughly into two further clades, one for East/Central Africa and another for West Africa. The genomic sequences of the Brazilian variety are closely tied to the Cambodian and Malaysian genomes in the non-African clade, thus implying that the Brazilian ZIKVs belong to the Asian clade. The phylogenetic tree shows that the Micronesia genome of 2007 is part of this Asian clade and indicates, as reasoned by Duffy et al. ${ }^{12}$ and Haddow et al., ${ }^{13}$ that the virus was probably carried from Asia by a viremic human to Micronesia or by a stray infected mosquito that was carried into Micronesia by the ubiquitous communication network, a probable course that could be easily replicated in case of other viral epidemics in the future.

The difference between the African and Asian ZIKV genomes is more clearly brought out in a two-dimensional (2D) representation of the nucleotide sequence. ${ }^{42}$ The $2 \mathrm{D}$ graphical representation for two genomes of the ZIKV-one from the Central African Republic in 1976 and another from Brazil in 2015-are shown in Figure 4. ${ }^{42,43}$ Since the plot follows the sequence in order and since the structural gene sequences constitute 2,489 (23.03\%) bases out of 10,807 bases of a typical genome (Table 4), we can see that for about a quarter of the sequence comprising the structural genes 


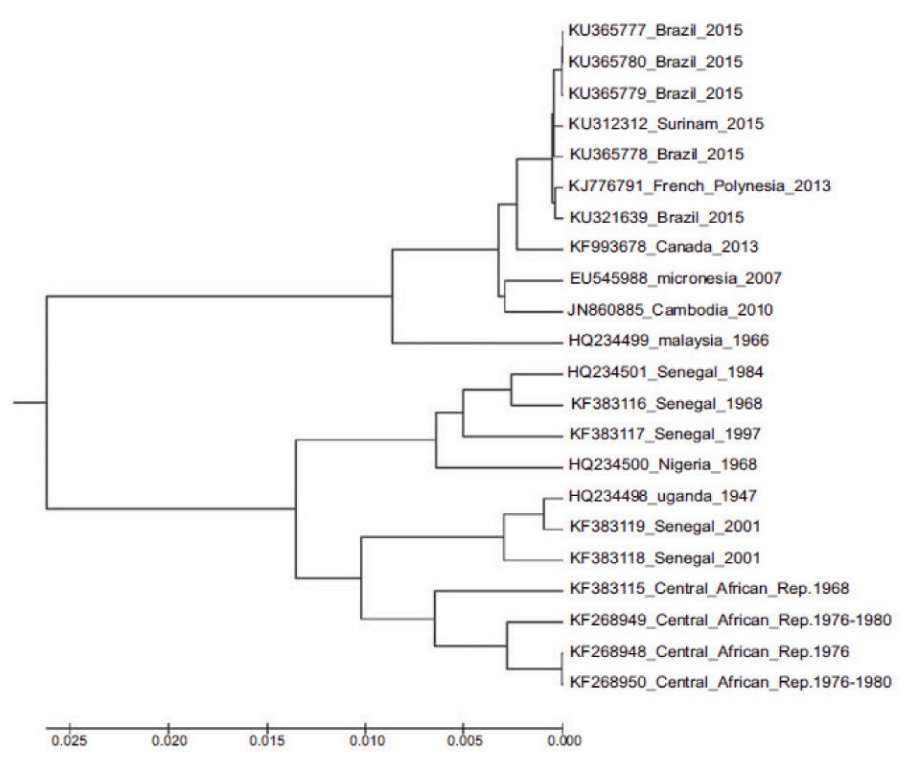

Fig. 3. Phylogenetic tree of 22 ZIKV genome sequences. Nandy et al. ${ }^{42}$ Abbreviation: ZIKV, Zika virus. Reproduced with permission from Bentham Science Publishers, www.benthamscience.com.

the two curves overlap, but then there is a divergence that carries on to the end, implying significant differences in one or more of the NS genes. A choice of different axes assignments and counting methods within the 2D graphical representation systems show dramatic differences between the representations of the genomes of African and Asian lineages arising from differences in their base distributions. ${ }^{42,44}$ The two methods allow quantitative measures of the differences and permit mathematical characterization of the genomic sequences.

In terms of nucleotide sequence identity between the various Zika strains, sequence alignment shows that the conserved bases amount to $87.06 \%$ for the strains comprising the African clade compared to $92.6 \%$ for the Asian clade; overall, the conserved bases amount to $79.05 \%$ of total bases. ${ }^{42}$ The higher conservancy level seen in the Asian clade strains is considered as arising from the much lesser time they have had to change through mutations, whereas the African clade strains, being comparatively older by decades, have had the time for many mutational changes. ${ }^{42}$

Lanciotti et al. ${ }^{45}$ have shown that the Uganda MR766 ZIKV and the Yap Island Zika strains have 96\% conservancy in their protein sequences, which the authors suggest could be the result of selective pressures arising from virus replication adapted to vertebrate hosts and arthropod vectors. This is also borne out by the $\mathrm{Ka} / \mathrm{Ks}$ (asynonymous to synonymous) ratios for the various coding regions of ZIKV computed by Zhu et al. ${ }^{35}$ which showed that these ratios for ZIKV strains were comparatively low, implying that these genes were under stabilizing selection pressure. Note, however, the observations of Giri et al. ${ }^{46}$ from their study of the ZIKV proteome (strain MR766) that revealed abundant intrinsically disordered regions in the capsid, NS2B, NS3, NS4A and NS5 proteins

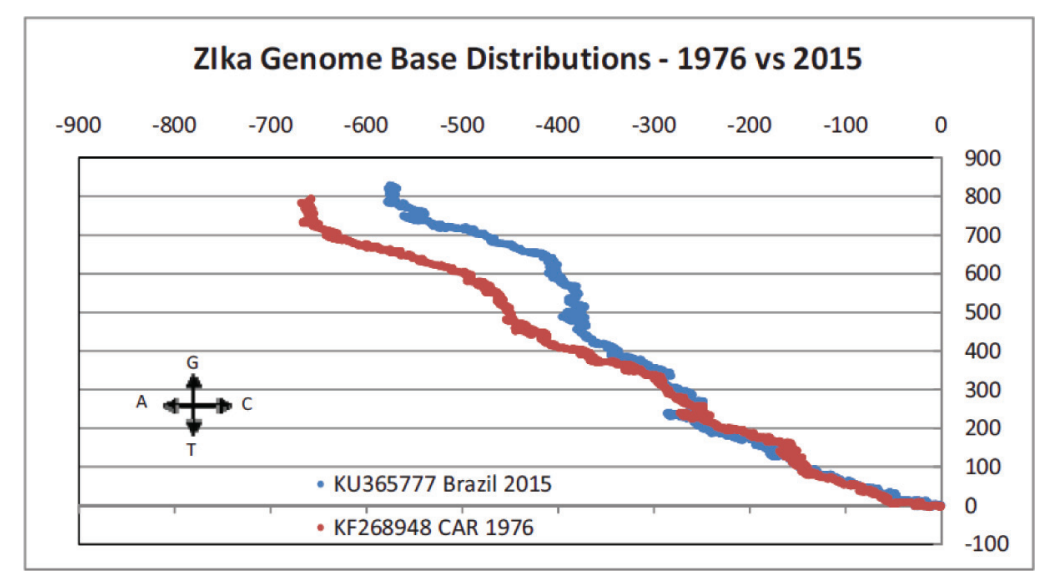

Fig. 4. Comparison of ZIKV genomes from Central African Republic 1976 to Brazil 2015 in $2 D$ graphical representation. ${ }^{42}$ Axes AGCT as shown in the inset. The algorithm involved starting at the origin and plotting a point for each base in the nucleotide sequence by a step in the $x y$-plane defined by $A(-1,0)$, $C(+1,0), G(0,+1), T(0,-1)$ until the end of the sequence, thus plotting a graph that reflects the base distribution and composition of the sequence. ${ }^{43}$ Abbreviations: 2D, two-dimensional; ZIKV, Zika virus. Reproduced with permission from Bentham Science Publishers, www.benthamscience.com. 
that contribute to structural plasticity and functional diversity in their role in mature particle formation and replication.

\section{The ZIKV proteins}

The complex polyprotein of the ZIKV bears low similarity to the polyproteins of other closely related flaviviruses, viz., SPONV $(68.3 \%$ to $69 \%$ nucleotide similarity in the strains studied and DENV2 (58.1\% to $58.9 \%$ nucleotide similarity). ${ }^{35}$ The 10 structural and NS proteins contain multiple transmembrane domains, with the majority being accounted for by NS2A, NS2B, NS4A and NS4B. ${ }^{35} \mathrm{~A} 2 \mathrm{~K}$ protein is generated by cleavage at the signal sequence of the NS4B; Kuno and Chang has discussed the cleavage sites in ZIKV and related other viral genomes in detail. ${ }^{34}$ The different genes encoding for the proteins making up the ZIKV play important roles in viral pathogenicity, replication and assembly, some of which are briefly described below.

$\mathrm{PrM} / \mathrm{M}-\mathrm{A}$ protein that along with the E protein forms heterodimers, essential prerequisite for formation of immature virions. Subsequently, the prM is cleaved and replaced by the M protein to produce and release mature virions.

E-A surface protein that is involved in viral attachment, fusion, penetration and hemagglutination. One hundred and eighty E proteins make up the icosahedral shell of the virion. The Zika virion is different from other flaviviruses, in that around 10 amino acids surround the Asn154 glycosylation site in each of the Zika E proteins. ${ }^{36}$ The E protein exists as a dimer in the mature virion, each protein having three domains: Domain I, harboring the glycosylation sites; Domain II, serving as the fusion protein; and Domain III, flanking one side of domain I and serving as the major antigenic region in the E protein. The receptor binding site is located in domain III, making it an important target for therapeutics and vaccine development.

NS1 - The first NS protein, NS1, plays a complex role in viral replication and pathogenesis. First reported in the sera of DENVinfected patients, it is well conserved among all the flaviviruses. As reported by Muller and Young, ${ }^{37}$ NS1 protein is found in multiple oligomeric forms and in different cellular structures, such as the cell-membrane bound form, on the cell surface and as a secreted soluble hexameric lipoparticle. It facilitates viral replication through its role as an essential co-factor. The secreted form of NS1 is implicated in immune evasion, while secreted and cell surface NS1 and the antibodies they elicit are believed to play contradictory roles of prevention and pathogenesis in the infected host.

Freire et al. $^{38}$ measured the synonymous codon usage for a range of ZIKV strains and found significant differences in codon usage for the entire polyprotein in the African and Asian lineages. In particular, for NS1, which, amongst the samples studied, had 91.8\% amino acid conservancy, codon usage bias in recent Asian lineage strains was higher as also in NS4A, and codon adaptation index that measures efficiency of adaptation to a host was also higher for humans and mosquitoes. Freire et al. ${ }^{38}$ also observed high levels of secretion of NS4A proteins, like for NS1 proteins, by infected cells, which they believe is significant since both NS1 and NS4A play important roles in viral replication, while NS4A helps viral survival by inhibiting cell death by up-regulation. Zhu et al. ${ }^{35}$ suggest that NS1 is required to initiate RNA genome synthesis.

NS2A, NS2B, NS4A, NS4B-These NS proteins are small and hydrophobic, but with functions not yet well understood and having no known enzymatic motifs. ${ }^{35}$ A comprehensive analysis by the same authors of the closely related Zika and SPONVs in terms of phylogenetic relationships showed that while the tree topology was almost similar for all the proteins, in the case of NS2B there is a difference, which the authors suggest probably arose from gene recombination events between the two types of viruses. The NS2B protein is also involved in cleavage of the viral polyproteins through its interaction with the $\mathrm{C}$-terminal protease domain of NS3.

NS3 is a multifunctional replication-oriented protein that, along with NS5, encodes the major viral enzymes of flaviviruses. The Nterminus of NS3 is involved in protease activity, while the C-terminal domain is involved in ATPase, helicase and other enzymatic activities. The C-terminal NS3 helicase is crucial to the survival and life cycle of ZIKV, and, therefore, constitutes suitable target for antivirals. Ramharak et al. ${ }^{39}$ have shown through molecular dynamics studies that an inhibitor like NITD008 effectively constrains ZIKV replication in vitro and in vivo. Jain et al. ${ }^{40}$ have shown through their NS3 structure determination that the NS3 helicase is closely similar to other flaviviruses, like DENV, and has three domains of roughly equal size ( $\sim 145$ residues). Domains 1 and 2 comprise tandem $\alpha / \beta$ RecA-like folds, characteristic of the helicase superfamily. ATP binds to the bottom of the cleft between domains 1 and 2 and the RNA is accommodated in a tunnel between domains 1 and 2 and domain 3; this domain has been implicated in interactions with the RNA-dependent RNA polymerase NS5 in other flaviviruses. Their studies with FTMap determined that there are two prominent drug or ligand binding sites that occur between domains 1 and 2 and at the junction of domains 1 and 3. Moreover, the two sites are situated close enough that it may be possible to design inhibitors that span both sites. Molecular dynamic studies by Oguntade et al. ${ }^{47}$ also determined three potent inhibitors of the NS3 helicase (Lapachol, HMC-HO1 $\alpha$ and Ivermectin) binding at the ATPase and single-stranded RNA site.

NS5-The largest of the ZIKV proteins, NS5 is a critical component in replication of the ZIKV RNA genome. The N-terminal part contains a methyltransferase (MT) domain, followed by a short linker that connects to the C-terminal part that contains the RNA-dependent RNA polymerase. Translation of the polyprotein is facilitated by the MT that adds the $5^{\prime}$-RNA cap structure, while the RNA-dependent RNA polymerase functions to initiate RNA synthesis; the MT also plays a role in inhibiting host innate immunological response. Zhao et al. ${ }^{41}$ determined that, structurally, the ZIKV NS5 shows remarkable similarity to other flavivirus NS5s and active sites are well conserved. These findings have indicated nucleoside analogues that can inhibit the polymerase activity of yellow fever virus, WNV and DENV and can also inhibit the ZIKV.

3'-UTR - This region has a role in viral replication and translation, and defects in the conserved regions can significantly affect the survival and pathogenicity of the virus. ${ }^{34}$

\section{Genetics of the ZIKV epidemic}

While a plethora of research on ZIKV has consumed the scientific world in the last 2 years following the ZIKV pandemic, the abiding problem that is still not resolved is the cause behind the sudden epidemic form of ZIKV as it spread to Oceania and South America. Does the answer lie in any significant changes in the virus, or does the answer lie in some characteristics of the host population? On the latter possibility, Kindhauser et al. ${ }^{3}$ speculated that perhaps the African and Asian populations being exposed to many diseases with similar symptoms, such as malaria, DENV, chikungunya and the like, over many generations had developed immunological characteristics that thwarted the neurotropic effect of ZIKV, but substantive proof of this assertion is yet to be established. As pointed out by Russel, ${ }^{48}$ increase in vector population also does not explain the epidemic since the Aedes group of mosquitoes have 
been present in tropical and sub-tropical South America, supporting DENV and chikungunya, for many years.

Considerable amount of effort has been devoted to the first alternative. Zhu et al. ${ }^{35}$ in their detailed study of Asian lineage preepidemic and epidemic strains of ZIKV found 24 amino acid substitutions in various proteins of the epidemic strain polyprotein, four of which (T773M, Y2082H, L2451S and T2630V) affected the hydropathy profile. Comparison with the African lineage displayed many more (75) amino acid substitutions, most of which had to do with the separation of the African and Asian lineage. However, 15 substitutions were specific to the epidemic strains. They found V603I and D679E substitutions in domain 3 of the envelope protein and found the I and $\mathrm{E}$ amino acids in those positions in all epidemic strains. They also found differences in the RNA secondary structures of the 5'- and 3'-UTRs of epidemic ZIKV compared to the pre-epidemic strains.

Russel suggested that codon usage bias in the epidemic strains could be the source of the increased pathogenicity of the ZIKV ${ }^{48}$ $\mathrm{He}$ also reported that immune enhancement by pre-existing antiflavivirus antibodies could be a contributing factor, as in the case of DENV, making the virus more pathogenic. Combination of both these factors could have led to the increased virulence observed for ZIKV infections in South America. Freire et al. ${ }^{38}$ detailed codon usage differences in the NS1 gene as a contributing factor to the Zika epidemic.

Ganguly and Ganguly determined by BLAST sequence analysis similarities in sequences of ZIKV NS4B and the human astroactin2 (astn2) gene. ${ }^{49}$ The astroactin2 protein is expressed at high levels during fetal development, and mutations in it can be associated with microcephaly in humans. The authors hypothesized that since both ZIKV NS4B and human astn2 are transmembrane proteins, they may co-localize and interact at pre-translational stages to cause microcephaly. However, why such situations did not develop in Africa or Asia, where presumably astn2 is also active, is not clear.

Perhaps the answer to the questions posed in the beginning of this section could be that both aspects, changes in ZIKV in the epidemic forms and the immunological status of the local host population, could form the lethal combination that gave rise to the neurological damages noticed in the epidemic ZIKV infections.

\section{Drugs and vaccines for ZIKV}

No drugs or vaccines are available against the ZIKV as of yet, but several strategies are being pursued by researchers on their design and development. ${ }^{46,50-55}$ Among the most recent, Balasubramanian et al. ${ }^{56}$ for example, have determined three compounds-quinacrine, mefloquineand GSK369796-that inhibit viral replication and therefore show anti-viral activity against DENV2 and ZIKV; Ramharack et al. ${ }^{39}$ suggested the NS3 protein as suitable target for inhibitor design.

On the other hand, considering that for some of the other human infecting flaviviruses (e.g., the WNV and the JEV) vaccines have been available for some time, the National Institute of Allergic and Infectious Diseases (NIAID) of the National Institute of Health (USA) worked on developing a DNA vaccine against ZIKV based on the WNV vaccine.${ }^{57}$ Phase 1 trials having given encouraging results, the vaccine was entered into a Phase 2 critical trial in March 2017, results of which are awaited. In the meantime, the Walter Reed Army Institute of Research (USA) launched a Phase 1 trial of a purified inactivated vaccine against the ZIKV based on their previous experience with DENV and JEV. A live-attenuated ZIKV vaccine developed at the NIAID is undergoing Phase 3 trials in
Brazil, and several other investigational approaches are under way. At last count, ClinicalTrials.gov, ${ }^{\mathbf{5 8}}$ an arm of the National Institute of Health, listed 16 studies for ZIKV vaccines. Many private firms, such as GlaxoSmithKline Pharma (USA) and SEEK (London), are working on various strategies for a ZIKV vaccine, ${ }^{57}$ while Bharat Biotech (India) is reported to be undertaking pre-clinical trials for a Zika vaccine, Zikavac. ${ }^{59}$

There are many other ideas for a ZIKV vaccine design. Taking a cue from the JEV situation, Zhu et al. ${ }^{35}$ recommended the glycosylation site in the prM-E complex, where a single amino acid substitution may elicit increased humoral host immune response, and domain 3 of the E protein, which contains the receptor binding site, as useful targets for vaccine design. Peptide vaccine that is strongly focused on generating appropriate immune response is an alternative strategy that has been put forward by several authors, ${ }^{60-62}$ though some technical problems remain. ${ }^{63}$

Shawan et al. ${ }^{64}$ predicted peptide vaccine targets using immunoinformatics tools within the Immune Epitope Analysis Resource and Database to identify peptides at the ZIKV protein sequence positions 121 and $117-137$ as most potent B cell linear and conformational epitopes, respectively. They also predicted highly potent T-cell epitopes at protein sequence position 250-258. Dey et $a l .{ }^{65}$ performed an analysis spanning conserved surface exposed regions with linear and conformational epitopes from a selection of complete and partial ZIKV envelope proteins, and identified a set of three peptide segments that could form the basis of peptide vaccines.

The issue is much broader than just to design a drug or vaccine for the ZIKV. The issue is the strategies to adopt to combat recurring bouts of epidemics from existing or new, zoonotic viruses and management of those strategies. Basak and Nandy have recounted the difficulties and costs associated with development of effective drugs and vaccines for use in the field and computational strategies that have been devised to combat these issues. ${ }^{66}$ Bhattacharjee and Basak have outlined the strategies that could be adopted for drug development against particular viruses like ZIKV, ${ }^{67}$ and Nandy and Basak have outlined the importance of management of the strategies, ${ }^{68}$ albeit in another viral context. The recent work by Dey et al. ${ }^{65}$ establishing a vaccine against the ZIKV is one strategy of peptide vaccine design to contain and prevent infections from the ZIKV.

\section{Future research prospective}

As this review shows, the reasons behind the sudden transformation of the ZIKV from an apparently benign form to one with severe neurologic complications continues to remain a mystery. It is sure to continue to be a main line of research activity, since the underlying causes could have implications for other viruses, and perhaps other flaviviruses, to also become neurotropic. One of the aspects that will come under close scrutiny arises from the ZIKVs' close proximity to DENV type 2, viz., whether the ZIKV will also show possibilities of antibody dependent enhancement, an affliction that has caused severe hemorrhage in repeat DENV patients, often leading to fatalities. The next mosquito season may shed some light on that.

The most intense research will surely continue in the areas of drug and vaccine development against the ZIKV. The success of the off-the-table vaccine against Ebola has raised hopes that a similar result could be anticipated with the ZIKV in view of the available vaccines and research programs in the case of the other human infecting flaviviruses, but no drugs or vaccines have reached the 


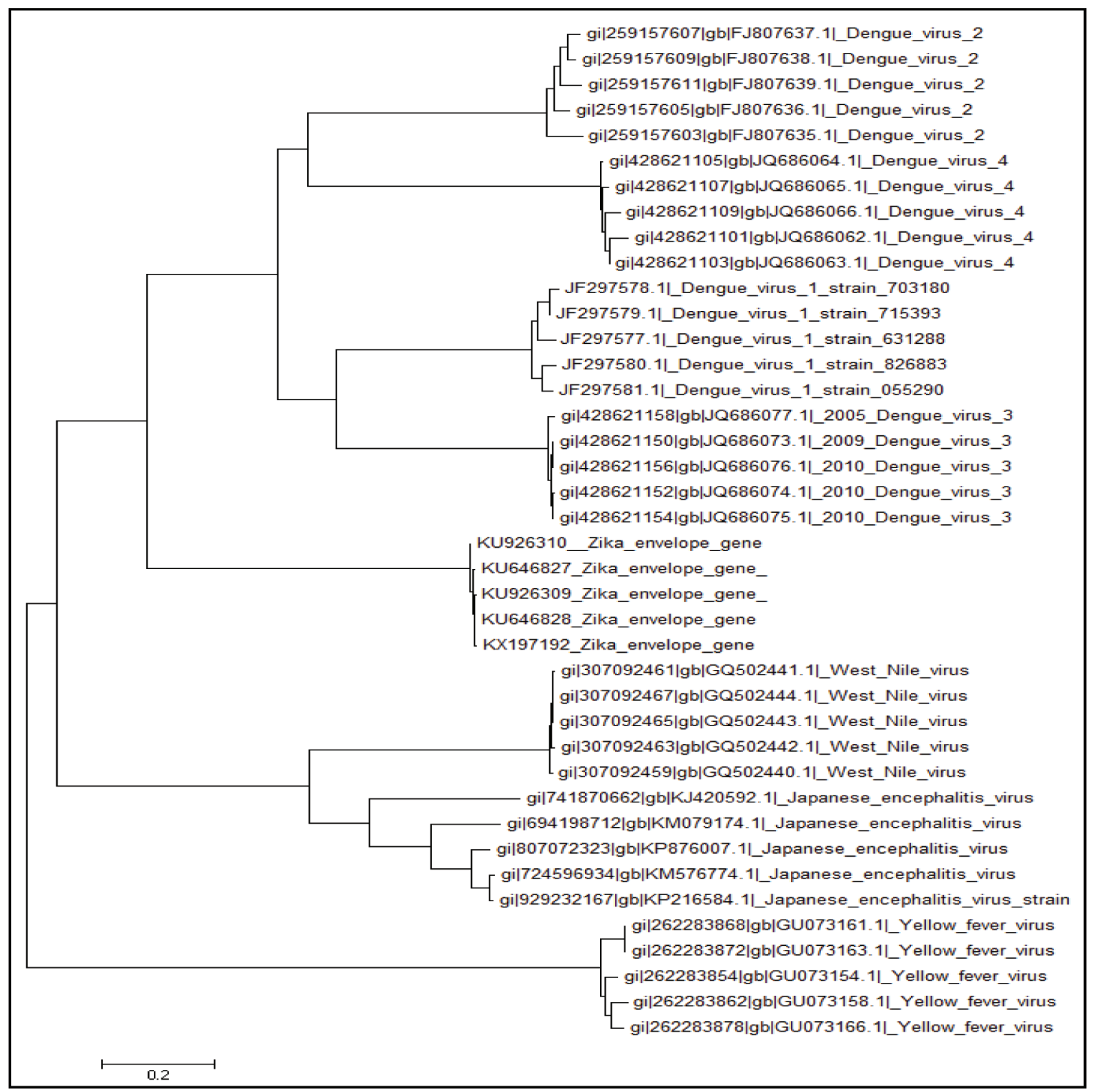

Fig. 5. Phylogenetic relationship between the E gene sequences of different Flavivirus members from various countries. Dey et al. ${ }^{70} \mathrm{Abbreviation:} \mathrm{E}$, envelope. Reproduced with permission from copyright holders.

clinical use stage as yet.

For some researchers with a more fundamental outlook, the rampage of ZIKV gives rise to a need to understand, at some basic level, what causes these sudden eruptions of virulent strains. We have seen cases of the swine flu (i.e. H1N1), the SARS and MERS epidemics, the Ebola crises and myriad other epidemics, of which the ZIKV is the latest and one with very far-reaching consequences. The question is whether we can extract some lessons from these experiences and prepare mankind to defend against possible epidemics reasonably earlier, ${ }^{69}$ whether there are perceptible clues that could help in this task, or whether we are constrained to always fight the conflagrations after the events. Given the growth in human population, climate change, insect menace, increasing urbanization and other concomitants of civilization, these are is- sues to consider, however remote the solutions may seem today.

\section{Summary}

The saga of the ZIKV is perhaps only in its beginning stages. From its identified origins in an obscure tropical forest in Uganda, it had spread through its natural vectors like A. aegypti and other Aedes species mosquitoes and unwitting travelers who may have carried the virus to new locales. Within half a century the virus had already made its way to other countries in tropical Africa and in South and South East Asia, Indonesia and the Philippines. The spread of the new virus evoked only sporadic illnesses reminiscent of DENV, chikungunya and the like, thus masking its nature and identity 
enough to be considered benign when recognized.

All that changed after epidemics in 2007 and 2013 in certain Pacific islands and in 2015-2016 in Brazil and several Latin America countries. Unusually high levels of microcephaly in fetal and neonatal cases, GBS and neurological disorders, recognized as being associated with ZIKV infections, raised serious concerns. The high level of urbanization that facilitates easy contamination, global warming that increases the reach of the vectors to newer areas, mega events like the Olympics that let people from various countries come into close contact, heightened levels of travel and shipments, all could contribute to further spread of the virus.

The reason that the virus that was relatively benign in the preepidemic period and suddenly became so highly pathogenic as to cause neurological dysfunctions in fetuses and neurotropic disorders in children and adults is yet to be understood. Amino acid substitutions could be one key; other keys may include local host immunologic status, vector infectivity and perhaps other as yet unrecognized issues. It is also not understood what causes only 1 in 10 fetuses of Zika-infected mothers to develop birth defects. ${ }^{11}$

$\mathrm{ZIKV}$, a member of the Flavivirus family, is a positive-sense single-stranded RNA virus whose genome consists of a polyprotein that codes for 10 structural and non-structural proteins. Genomic analyses have revealed several mutations in the genomes of the virus in Africa, Asia and the Americas that indicate a pronounced shift between the African and Asian lineages, but the American genomes line up quite well with the Asian strains. Phylogenetic analysis reveals distinct clades for the African and Asian lineages; comparison with other human infecting flaviviruses (Fig. 5) shows each member of the family in distinct clades, in which DENV type 2 is found closest to ZIKV. ${ }^{70}$

Repeat infections in case of DENV can cause antibody-dependent enhancement, leading in some cases to severe hemorrhage and death. The Zika epidemic is too recent to estimate the danger of a second infection, but since ZIKV and DENV are of the same Flavivirus family, with ZIKV being phylogenetically closest to DENV2 among the four DENV types, the possibility of antibody-dependent enhancement-type reactions and symptoms cannot be ruled out at present.

However, whatever may be the reasons behind the transformation into a highly pathogenic form, development of suitable drugs and vaccines against ZIKV has to take priority. Several small molecules have been proposed to inhibit viral replication and multiple vaccine candidates are in various trial phases and more are on the way. Peptide vaccines could hold one key to longer lasting solutions since these are predicated upon conserved segments, ${ }^{65}$ but the statistics remain poor at this time. ${ }^{63}$

While Zika viral infections could be on the downswing in mid2017 , the trials and tribulations of the last 2 years show the importance of understanding viral epidemics and vaccine preparedness and whether the entire exercise could be done faster in case of new outbreaks. ${ }^{69}$ New strategies, preferably computer-assisted ones, ${ }^{66,67}$ are required to manage the burden of viral epidemics that may arise from new and emerging viruses that have adapted adequately to infect humans. In the meantime, only governmental efforts to curtail mosquito prevalence and issuance of advisories for citizens remain the main efforts to combat the menace of the new virus. Institutions like the CDC and WHO provide timely alerts and warnings, and individuals have to protect themselves from mosquito bites and contacts with infected persons - all until a reasonably dependable regimen against the virus is devised.

\section{Acknowledgments}

The authors wish to express their thanks to the learned referees for their very insightful comments and suggestions, responses to which have helped to improve the quality of the review.

\section{Conflict of interest}

The authors have no conflict of interests related to this publication.

\section{Author contributions}

Both authors contributed equally to the study design and completion, and to the writing of the manuscript.

\section{References}

[1] Dick GW, Kitchen SF, Haddow AJ. Zika virus. I. Isolations and serological specificity. Trans R Soc Trop Med Hyg 1952;46:509-520. doi:10.1016/0035-9203(52)90042-4.

[2] Shuman EK. Global climate change and infectious diseases. N Engl J Med 2010;362:1061-1063. doi:10.1056/NEJMp0912931.

[3] Kindhauser MK, Allen T, Frank V, Santhana RS, Dye C. Zika: the origin and spread of a mosquito-borne virus. Bull World Health Organ 2016;94(9):675-686C. doi:10.2471/BLT.16.171082.

[4] Campos GS, Bandeira AC, Sardi SI. Zika virus outbreak, Bahia, Brazil. Emerg Infect Dis 2015;21(10):1885-1886. doi:10.3201/eid2110. 150847.

[5] Petersen LR, Jamieson DJ, Powers AM, Honein MA. Zika virus. N Engl J Med 2016;374:1552-1563. doi:10.1056/NEJMra1602113.

[6] WHO 2017. Regional Zika epidemiological updates (Americas), April 27, 2017. [Accessed 14th May 2017]. Available from: http://www. paho.org/hq/index.php?option=com_content\&id=11599\&/tem id $=41691$.

[7] Rasmussen SA, Jamieson DJ, Honein MA, Petersen LR. Zika virus and birth defects - Reviewing the evidence for causality. N Engl J Med 2016;374:1981-1987. doi:10.1056/NEJMsr1604338.

[8] WHO Director-General summarizes the outcome of the Emergency Committee regarding clusters of microcephaly and Guillain-Barré syndrome". World Health Organization. [Accessed 26 May 2017]. Available from: http://www.who.int/mediacentre/news/statements/2016/ zikafifth-ec/en/.

[9] Centers for Disease Control and Prevention: Facts about Microcephaly. [Last updated December 7, 2016]. Available from: https://www. cdc.gov/ncbddd/birthdefects/microcephaly.html.

[10] Bhide P, Kar A. Birth prevalence of microcephaly in India. [Submitted]. Bull World Health Organ E-pub:23 Feb 2016. doi: 10.2471/ BLT.16.172080.

[11] Vital Signs: Update on Zika virus-Associated birth defects and evaluation of all U.S. infants with congenital Zika virus exposure - U.S. Zika Pregnancy Registry, 2016. MMWR 2017;66(13):366-373.

[12] Duffy MR, Chen TH, Hancock WT, Powers AM, Kool JL, Lanciotti RS, et al. Zika virus outbreak on Yap Island, Federated States of Micronesia. N Engl J Med 2009;360(24):2536-2543. doi:10.1056/NEJMoa0805715.

[13] Haddow AD, Schuh AJ, Yasuda CY, Kasper MR, Heang V, Huy R, et al. Genetic characterization of Zika virus strains: geographic expansion of the Asian lineage. PLoS Negl Trop Dis 2012;6(2):e1477. doi:10.1371/journal.pntd.0001477.

[14] LaBeaud A.D. Zika virus infection: An overview. [Updated May 15, 2017, Accessed 18th May 2017]. Available from: http://www.uptodate.com/contents/zika-virus-infection-an-overview.

[15] Dasgupta S, Reagan-Steiner S, Goodenough D, Russel K, Tanner M, Lewis L, et al. Patterns in Zika Virus Testing and Infection, by Report of Symptoms and Pregnancy Status - United States, January 3-March 5, 2016. MMWR Morb Mortal Wkly Rep 2016;65:395-399. doi:10.16/ mmwr.mm6515e1.

[16] Epidemiological alert 2015. Neurological syndrome, congenital 
malformations, and Zika virus infection. Implications for public health in the Americas. 1 Dec 2015 [Internet]. Washington: Pan American Health Organization; 2015. [Accessed 26 May 2017]. Available from: http://www.paho.org/hq/index.php?option=com docman\&task=doc_download\&ltemid=\&gid=32405.

[17] Musso D, Gubler DJ. Zika virus. Clinical Microbiol Rev 2016;29(3):487524. doi:10.1128/CMR.00072-15.

[18] Cayne CB, Lazear HM. Zika virus - reigniting the TORCH. Nat Rev Microbiol 2016;14:707-715. doi:10.1038/nrmicro.2016.125.

[19] CDC Travel Notices. [Updated March 10, 2017]. Available from: https://wwwnc.cdc.gov/travel/notices.

[20] Roa M. Zika virus outbreak: Reproductive health and rights in Latin America. Lancet 2016;387(10021):843. doi:10.1016/S01406736(16)00331-7.

[21] Cao-Lormeau VM, Blake A, Mons S, Lastere S, Roche C, Vanhomwegen J, et al. Guillain-Barré Syndrome outbreak associated with Zika virus infection in French Polynesia: a case-control study. Lancet 2016;387(10027):1531-1539. doi:10.1016/S0140-6736(16)00562-6.

[22] Parra B, Lizarazo J, Jiménez-Arango JA, Zea-Vera AF, González-Manrique G, Vargas J, et al. Guillain-Barré Syndrome associated with Zika virus infection in Colombia. N Engl J Med 2016;375:1513-1523. doi:10.1056/NEJMoa1605564.

[23] Epidemiological alert 2015. Zika virus infection. 7 May 2015 [Internet]. Washington: Pan American Health Organization; 2015. [Accessed 26 May 2017]. Available from: http://www.paho.org/hq/ index.php?option=com_docman\&task=doc_view\&Itemid=270\&gid= 30075=en.

[24] Epidemiological alert 2015. Increase of microcephaly in the northeast of Brazil. 17 November 2015 [Internet]. Washington: Pan American Health Organization; 2015. [Accessed 26 May 2017] Available from: http://www.paho.org/hq/index.php?option=com docman\&task=doc_view\&ltemid=270\&gid=32285.

[25] CDC: Zika virus. Centers for Disease Control and Prevention/ National Center for Emerging and Zoonotic Infectious Diseases (NCEZID)/ Division of Vector-Borne Diseases (DVBD). [Updated May 25, 2017] Available from: https://www.cdc.gov/zika/.

[26] WHO 2017. Emergencies preparedness, response. Disease outbreak news, 26th May 2017. [Accessed 27th May 2017]. Available from: http://www.who.int/csr/don/26-may-2017-zika-ind/en/.

[27] Priye A, Bird SW, Light YK, Ball CS, Negrete OA, Meagher RJ. A smartphone-based diagnostic platform for rapid detection of Zika, chikungunya, and dengue viruses. Sci Rep 2017;7:44778. doi:10.1038/ srep44778.

[28] CDC 1 May 2017, Treatment. Available from: https://www.cdc.gov/ zika/symptoms/treatment.html.

[29] Horton R. Offline: Brazil-the unexpected opportunity that Zika presents. Lancet 2016;387:633. doi:10.1016/S0140-6736(16)00268-3.

[30] CDC 4 April 2017, Pregnancy. Available from: https://www.cdc.gov/ zika/pregnancy/index.html.

[31] CDC 4 April 2017, Pregnancy. Available from: https://www.cdc.gov/ zika/pregnancy/index.html.

[32] Haddow AD, Nasar F, Guzman H, Ponlawat A, Jarman RG, Tesh RB et al. Genetic characterization of spondweni and Zika viruses and susceptibility of geographically distinct strains of Aedes aegypti, Aedes albopictus and Culex quinquefasciatus (Diptera: Culicidae) to Spondweni virus. PLoS Negl Trop Dis 2016;10(10):e0005083. doi:10.1371/journal.pntd.0005083.

[33] Grard G, Moureau G, Charrel R, Holmes EC, Gould EA, de Lamballerie $X$. Genomics and evolution of Aedes-borne flaviviruses. J Gen Virol 2010;91(Pt 1):87-94. doi:10.1099/vir.0.014506-0.

[34] Kuno G, Chang GJ. Full-length sequencing and genomic characterization of Bagaza, Kedougou, and Zika viruses. Arch Virol 2007;152:687696. doi:10.1007/s00705-006-0903-Z.

[35] Zhu Z, Chan JF-W, Tee K-M, Choi K-Y, Lau SK-P, Woo PC-Y, et al Comparative genomic analysis of pre-epidemic and epidemic Zika virus strains for virological factors potentially associated with the rapidly expanding epidemic. Emerg Microbes Infect 2016;5:e22. doi:10.1038/emi.2016.48

[36] Sirohi D, Chen Z, Sun L, Klose T, Pierson TC, Rossmann MG, et al. The $3.8 \AA$ resolution cryo-EM structure of Zika virus. Science 2016;352(6284):467-470. doi:10.1126/science.aaf5316.
[37] Muller DA, Young PR. The flavivirus NS1 protein: Molecular and structural biology, immunology, role in pathogenesis and application as a diagnostic biomarker. Antiviral Res 2013;98(2):192-208. doi:10.1016/j.antiviral.2013.03.008.

[38] Freire CC de M, Lamarino A, de Lima Neto DF, Sall AA, de Andrade Zanotto PM. Spread of the pandemic Zika virus lineage is associated with NS1 codon usage adaptation in humans. bioRxiv 2015, preprint. doi:10.1101/032839.

[39] Ramharack P, Oguntade S, Soliman MES. Delving into Zika virus structural dynamics - a closer look at NS3 helicase loop flexibility and its role in drug discovery. RSC Adv 2017;7:22133-22144. doi:10.1039/ C7RA01376K

[40] Jain R, Coloma J, Garcia-Sastre A, Aggarwai AK. Structure of the NS3 helicase from Zika virus. Nat Struct Mol Biol 2016;23(8):752-754. doi:10.1038/nsmb.3258.

[41] Zhao B, Yi G, Du F, Chuang Y-C, Vaughan RC, Sankaran B, et al. Structure and function of the Zika virus full-length NS5 protein. Nature Comm 2017;8:14762. doi:10.1038/ncomms14762.

[42] Nandy A, Dey S, Basak SC, Bielinska-Waz D, Waz P. Characterizing the Zika virus genome - A bioinformatics study. Curr Comput Aided Drug Des 2016;12(2):87-97. doi:10.2174/1573409912666160401115812.

[43] Nandy A. A new graphical representation and analysis of DNA sequence structure: I. Methodology and Application to Globin Genes. Current Sc 1994;66(4):309-314.

[44] Panas D, Waz P, Bielinska-Waz D, Nandy A, Basak SC. 2D dynamic representation of DNA/RNA sequences as a characterization tool of the Zika virus genome. MATCH Commun Math Comput Chem 2017;77:321-332.

[45] Lanciotti RS, Kosoy OL, Laven JJ, Velez JO, Lambert AJ, Johnson AJ, et al. Genetic and Serologic Properties of Zika Virus Associated with an Epidemic, Yap State, Micronesia, 2007. Emerg Infect Dis 2008;14(8):1232-1239. doi:10.3201/eid1408.080287.

[46] Giri R, Kumar D, Sharma N, Uversky VN. Intrinsically disordered side of the Zika virus proteome. Front Cell Infect Microbiol 2016;6:144. doi:10.3389/fcimb.2016.00144.

[47] Oguntade S, Ramharack P, Soliman MES. Characterizing the ligandbinding landscape of Zika NS3 helicase-promising lead compounds as potential inhibitors. Future Virol 2017;12(6):261-273. doi:10.2217/ fvl-2017-0014.

[48] Russell PK. The Zika pandemic - A perfect storm?. PLoS Negl Trop Dis 2016;10(3):e0004589. doi:10.1371/journal.pntd.0004589.

[49] Ganguly B, Ganguly E. Disruption of human astn2 function by ZIKV ns4b gene as a molecular basis for Zika viral microcephaly. bioRxiv 2016, preprint. doi:10.1101/054486.

[50] Ekins S, Perryman AL, Andrade CH. OpenZika: An IBM world community grid project to accelerate Zika virus drug discovery. PLoS Negl Trop Dis 2016;10(10):e0005023. doi:10.1371/journal.pntd.0005023.

[51] Lim L, Roy A, Song J. Identification of a Zika NS2B-NS3pro pocket sus ceptible to allosteric inhibition by small molecules including qucertin rich in edible plants. bioRxiv 2016, preprint. doi:10.1101/078543.

[52] Tan H, Ji X, Yang X, Xie W, Yang K, Che C, et al. The crystal structure of Zika virus helicase: basis for antiviral drug design. Protein Cell 2016;7(6):450-454. doi:10.1007/s13238-016-0275-4.

[53] Zhao Y. Challenges in searching for Zika therapeutics. J Chem Biol Ther 2016;1(2):e102. doi:10.4172/2572-0406.1000e102.

[54] Coutard B, Barral K, Lichiere J, Selisko B, Martin B, Aouadi W, et al. Zika virus methyltransferase: structure and functions for drug design perspectives. J Virol 2017;91(5):e02202-16. doi:10.1128/JVI.0220216.

[55] Salam A, Rojek A, Dunning J, Horby PW. Clinical trials of therapeutics for the prevention of congenital Zika virus disease: challenges and potential solutions. Ann Intern Med 2017;166(10):725-732. doi:10.7326/M16-2530.

[56] Balasubramanian A, Teramoto T, Kulkarni AA, Bhattaacharjee AK, Padmanabhan R. Antiviral activities of selected antimalarials against dengue virus type 2 and Zika virus. Antiviral Res 2017;137:141-150. doi:10.1016/j.antiviral.2016.11.015.

[57] NIAID 2017. Zika virus vaccines. [Accessed June 11, 2017]. Available from: https://www.niaid.nih.gov/diseases-conditions/zika-vaccines.

[58] ClinicalTrials.gov. 2017. [Last accessed 20th June 2017]. Available online: https://www.clinicaltrials.gov/ct2/results?term=zika+virus+vac 
cines\&Search=Search.

[59] Bagla P. How Bharat Biotech made its breakthrough in developing a vaccine for Zika virus. Huffington Post, New Delhi [PTI. Retrieved 9 February 2016].

[60] Purcell AW, McCluskey J, Rossjohn J. More than one reason to rethink the use of peptides in vaccine design. Nat Rev Drug Discov 2007;6(5):404-414. doi:10.1038/nrd2224.

[61] Sirskyl D, Diaz-Mitoma F, Golshani A, Kumar A, Azizi A. Innovative bioinformatic approaches for developing peptide-based vaccines against hypervariable viruses. Immunol Cell Biol 2011;89(1):81-89. doi:10.1038/icb.2010.65.

[62] Li W, Joshi MD, Singhania S, Ramsey KH, Murthy AK. Peptide vaccine: progress and challenges. Vaccines (Basel) 2014;2:515-536. doi:10.3390/vaccines2030515.

[63] Nandy A, Basak SC. Rational design of peptide vaccines against the Zika virus through sequence descriptors: techniques and problems. Int J Vaccine Res 2016;1(1):3.

[64] Shawan MMAK, Al Mahmud H, Hasan MdM, Parvin A, Rahman MdN, Rahman SMB. In Silico Modeling and Immunoinformatics Probing Disclose the Epitope Based Peptide Vaccine Against Zika Virus Envelope Glycoprotein. Indian J Pharm Biol Res 2014;2(4):44-57.
[65] Dey S, Nandy A, Basak SC, Nandy P, Das S. A bioinformatics approach to designing a Zika virus vaccine. Comput Biol Chem 2017;68:143152. doi:10.1016/j.compbiolchem.2017.03.002.

[66] Basak SC, Nandy A. Editorial - Computer-assisted approaches as decision support systems in the overall strategy of combating emerging diseases: some comments regarding drug design, vaccinomics, and genomic surveillance of the Zika virus. Curr Comp-Aided Drug Des 2016;12(1):2-4.

[67] Bhattacharjee AK, Basak SC. Spilled over emerging infectious diseases necessitate an accelerated drug design and discovery program: some comments with special reference to chemoinformatics and the current Zika virus crisis. Curr Comp-Aided Drug Des 2016;12(4):251252.

[68] Nandy A, Basak SC. Computer-assisted Vaccine Design (CAVD) approach can help in the management of the emerging H7N9 influenza virus. Curr Comp-Aided Drug Des 2017;13(3):1-2.

[69] Nandy A, Basak SC. Viral epidemics and vaccine preparedness. J Mol Pathol Epidemiol 2017;2:S1.

[70] Dey S, Das S, Nandy A. Characterization of Zika and other human infecting flavivirus envelope proteins and determination of common conserved epitope regions. EC Microbiol 2017;8(1):29-46. 